\title{
Differences in gram-positive bacterial colonization and antimicrobial resistance among children in a high income inequality setting
}

Felipe Piedade Gonçalves Neves ${ }^{1 *}$ (10, Mariel Asbury Marlow², Gabriel Rezende-Pereira', Marcos Gabriel Pinheiro³, Allyne Fandino Martinez dos Santos ${ }^{3}$, Maria de Fátima Nogueira de Freitas ${ }^{3}$, Rosana Rocha Barros ${ }^{1}$,

Fábio Aguiar-Alves ${ }^{3}$, Claudete Aparecida Araújo Cardoso ${ }^{4}$ and Lee Woodland Riley ${ }^{2}$

\begin{abstract}
Background: Staphylococcus aureus and beta-hemolytic streptococci (BHS) diseases disproportionately affect populations in middle/low-income countries. To assess if this disparity is reflected in colonization by these organisms, we compared their colonization frequency among children from different socioeconomic status (SES) communities in a city with high income inequality.

Methods: Between May-August 2014, we collected nasal and throat swabs to investigate S. aureus and BHS colonization among children who attended private and public pediatric clinics. Patients were classified as high SES, middle/low SES, and slum residents. We investigated the antimicrobial resistance profile, the SCCmec types and the presence of PVL genes among methicillin-resistant S. aureus (MRSA). We also examined the antimicrobial resistance profile and serogroups of BHS.
\end{abstract}

Results: Of 598 children, 221 (37\%) were colonized with S. aureus, of which 49 (22\%) were MRSA. MRSA colonization was higher in middle/low SES $(n=18 ; 14 \%)$ compared with high SES $(n=17 ; 6 \%)$ and slum $(n=14 ; 8 \%)$ residents $(p=0.01)$. All MRSA strains were susceptible to clindamycin, nitrofurantoin, and rifampin. The highest nonsusceptibility frequency (42.9\%) was observed to erythromycin. SCCmec type $V$ was only found in isolates from high SES children; types I and II were found only in middle/low SES children. Ten (20\%) MRSA isolates carried PVL genes. Twenty-four (4\%) children were BHS carriers. All BHS $(n=8)$ found in high SES children and six (67\%) isolates from slum patients belonged to group A. All group B streptococci were from middle/low SES children, corresponding to five $(71 \%)$ of the seven BHS isolated in this group. BHS isolates were susceptible to all drugs tested.

Conclusions: Children from different SES communities had distinct bacterial colonization profiles, including MRSA carriage. Public health officials/researchers should consider SES when assessing disease transmission and control measures.

Keywords: MRSA, Beta-hemolytic streptococci, Colonization, Health disparities, Income inequality

\footnotetext{
* Correspondence: fpgneves@id.uff.br

'Instituto Biomédico, Universidade Federal Fluminense, Niterói, RJ, Brazil

Full list of author information is available at the end of the article
}

(c) The Author(s). 2019 Open Access This article is distributed under the terms of the Creative Commons Attribution 4.0 International License (http://creativecommons.org/licenses/by/4.0/), which permits unrestricted use, distribution, and reproduction in any medium, provided you give appropriate credit to the original author(s) and the source, provide a link to the Creative Commons license, and indicate if changes were made. The Creative Commons Public Domain Dedication waiver (http://creativecommons.org/publicdomain/zero/1.0/) applies to the data made available in this article, unless otherwise stated. 


\section{Background}

Staphylococcus aureus and beta-hemolytic streptococci (BHS), including Streptococcus pyogenes (group A streptococci, GAS) and Streptococcus agalactiae (group B streptococci, GBS), are Gram-positive bacteria that cause a range of infections, from mild cutaneous and upper-respiratory infections to invasive bloodstream and respiratory infections [1-3]. They permeate our environment, and can be found in food, hospitals, schools, childcare centers, and households [4]. These bacteria, especially $S$. aureus and $S$. pyogenes, can also asymptomatically colonize the human upper respiratory tract and the skin, making their spread difficult to control in a population. In a susceptible host, colonization can be a major risk factor for disease [5].

In children, $S$. aureus is one of the organisms most frequently isolated from patients with healthcare-associated infections, causing not only skin and soft tissue infections, but also invasive infections, such as bacteremia, osteomyelitis and septic arthritis [6]. Despite the low mortality rate (1-2\%) for hospitalized children with methicillin-resistant $S$. aureus (MRSA) infection, there seems to be an increasing trend in the incidence of MRSA infections in such children [7]. Also, MRSA bacteremia in pediatric patients has been frequently associated with treatment failure and complications [8].

Methicillin resistance is encoded by genes organized in the staphylococcal cassette chromosome mec (SCCmec). To date, 13 SCCmec types (I-XIII) have already been described [9]. In addition, community-associated MRSA (CA-MRSA) strains often contains the Panton-Valentine leucocidin (PVL), which may be associated with severe diseases, such as necrotizing pneumonia [10].

The prevalence of GAS infections is higher among children, which is considered as a 'hazard' in school-aged children [11]. In addition, 319,000 infants were estimated to have disease caused by GBS globally in 2015, and approximately 7000 of these patients presented with neonatal encephalopathy [12].

While these pathogens represent a major public health burden among pediatric populations globally, diseases caused by these pathogens disproportionately affect populations in middle- and low-income countries [13]. Resource-poor communities, such as urban slums, have conditions that enhance the spread of bacteria, including crowding, untreated water, open sewage, and poor access to or uptake of health care services [14]. Although now classified by the World Bank as an upper-middle-income country in 2014, Brazilian cities have very high income disparity, with slum and high-income communities located in close proximity. Despite a high gross domestic product (GDP) of \$USD 1.79 trillion, over 11 million people live in informal settlements or slums in Brazil [15].

While the incidence of diseases caused by these Gram-positive bacteria differs between high-income vs. middle and low-income populations, colonization frequency and strain characteristics by socioeconomic status (SES) in children residing in the same city is not well characterized. As varying living conditions among communities may result in different disease prevalence and transmission pathways, we investigated $S$. aureus and BHS colonization patterns among children living in high and middle/low SES, and slum communities. We compared risk factors for colonization and drug resistance of the isolates by SES group in the same city.

\section{Methods}

\section{Study sites and population}

For this cross-sectional study, we recruited children who attended two private pediatric clinics and one public pediatric clinic for primary care or routine follow-up. Study clinics were located in the city of Niterói, in Rio de Janeiro metropolitan area, Rio de Janeiro state, Brazil. In 2014, the city had a population of approximately 488,000 [16] and a Gini index (an economic measure of inequality) of 0.60, a ranking consistent with Gini indexes of the 10 most unequal countries in the world [17]. The private clinics provide care for children who have private health insurance or who pay out-of-pocket; both clinics are located in the high-income neighborhood in the western section of the city. The public clinic provides free health care to any child through the Brazilian national public health care system (Unified Health System-Sistema Único de Saúde or SUS). The clinic is part of a primary care facility, located on the border between middle/low SES and slum neighborhoods in the eastern section of the city. The private clinics are $1.7 \mathrm{~km}$ apart from each other and approximately $8 \mathrm{~km}$ from the public clinic.

\section{Patient recruitment and specimen collection}

All children less than 18 years of age were consecutively recruited from May 12th to August 12th, 2014. Each of the clinics were sampled alternately for three half-day recruitment sessions per week. The number of recruited children was monitored weekly to assure corresponding sample size recruitment in each clinic per week. Age-appropriate written assent was obtained for children 7 years of age or older and verbal assent for children under 7 years of age. Following legal guardians' written consent, one nasal swab and one throat swab were obtained from each child. Swabs were immediately placed into a tube containing Stuart medium until transported to the laboratory on the same day. A questionnaire for clinical and socioeconomic data was completed by child's legal guardian using the mobile data collection application Magpi (Magpi, Washington, DC).

Laboratory processing and characterization of the isolates We used the mannitol salt agar to isolate staphylococcal colonies from nasal swabs and we identified $S$. aureus 
using catalase and coagulase tests. Staphylococcal isolates were tested for antimicrobial resistance against $30-\mu \mathrm{g}$ cefoxitin and $1-\mu \mathrm{g}$ oxacillin by the disk-diffusion method to identify MRSA strains [18]. Resistance was then confirmed by the presence of the mecA gene via polymerase chain reaction (PCR) [19]. Multiplex PCR was used to assess SCCmec type for MRSA isolates [19]. Presence of PVL genes was investigated by PCR [20]. BHS colonies were detected by culture on $5 \%$ sheep blood agar plates and their phenotypic identification was performed by determining the group carbohydrate antigen (Lancefield groups A, B, C, F, and G), susceptibility to $0.04 \mathrm{U}$ bacitracin and PYRase activity [21]. Antimicrobial susceptibility testing was performed by the disk-diffusion method on Mueller-Hinton agar (MHA) plate for MRSA strains and on MHA with 5\% sheep blood agar plate for BHS [18]. The antimicrobial agents tested for MRSA were: 5- $\mu$ g ciprofloxacin, 5- $\mu$ g chloramphenicol, $2-\mu \mathrm{g}$ clindamycin, $15-\mu \mathrm{g}$ erythromycin, 10- $\mu \mathrm{g}$ gentamicin, 300- $\mu \mathrm{g}$ nitrofurantoin, 5- $\mu \mathrm{g}$ rifampin, 1.25/ $23.75-\mu \mathrm{g}$ trimethoprim-sulfamethoxazole, and $30-\mu \mathrm{g}$ tetracycline. For BHS, the following antimicrobial agents were tested: $30-\mu \mathrm{g}$ ceftriaxone, $2-\mu \mathrm{g}$ clindamycin, $15-\mu \mathrm{g}$ erythromycin, 5- $\mu$ g levofloxacin, 10-UI penicillin G, $30-\mu \mathrm{g}$ tetracycline, and $30-\mu \mathrm{g}$ vancomycin.

\section{Data analysis}

We estimated that 600 children would be needed to detect a difference of $10 \%$ in MRSA and BHS colonization between private and public clinics, with a two-tailed $\alpha$ of 0.05 and a $(1-\beta)$ of 0.80 , for a comparison of two independent proportions. Final estimate accounts for a conservative $20 \%$ potential missing data/sample rate. This difference is based on previous studies on MRSA in the same city [22] and GAS in Salvador, Brazil [23].

For this analysis, we classified pediatric patients into three SES groups based on clinic attended and self-reported slum residence: high SES children were those who attended the private clinic and self-reported non-slum residence; middle/low SES were those children who attended the public clinic and self-reported non-slum residence; and slum children were those who attended either a public or private clinic and self-reported slum residence. To support the use of this SES classification, patient addresses were also geocoded with Google Maps API v3 and mapped in ArcGIS 10 (ESRI, Redlands, CA). Patient addresses were then overlaid with census tracts to determine proximity to or residence inside of a slum, defined by the Brazilian government as aglomerados subnormais (AGSN). An AGSN has at least 51 housing units on illegally occupied land with non-municipal approved construction or insecure access to essential public services [15].
Household salary is presented in USD based on the average USD:BRL exchange rate during the study period of 1:2.24 and categorized as multiples of the Brazilian monthly minimum wage in 2014 (USD \$324).

We used Chi-squared tests, or Fisher's exact tests (two-tailed) when appropriate, to assess associations between categorical variables and the outcomes of interest. We also used t-tests, or ANOVA tests when appropriate, to assess associations between continuous variables and the outcomes of interest. Variables found to have a statistically important association, defined as $p<0.10$, were included in the regression analysis. Factors significant in the bivariate logistic regression or suspected to be potential confounding factors were included by step-wise variable selection to build the multivariate regression model. Lack of fit of the regression model was assessed by failure to reject the Hosmer and Lemeshow Goodness-of-Fit Test. Statistical analyses were carried out in SAS University Edition (SAS Institute Inc., Cary, NC).

\section{Results}

Of 682 pediatric patients invited to participate, 598 $(88 \%)$ consented and were enrolled, including 298 children from private clinics and 300 children from public clinic. Non-participation frequency was $10 \%$ (33/332) in the private clinics and 14\% (50/350) in the public clinic. Most frequent reasons for non-participation included children who were vomiting or too fatigued to participate at recruitment, not enough time, and legal guardian under the age of 18 years.

Patient demographic characteristics were consistent with patient SES group, with high SES, middle/low SES, and slum groups, being significantly different across all demographic characteristics investigated except gender (Table 1). The mean age of children classified in high-income group was 3.2 years compared to 5.9 years for children from middle/low-income neighborhoods and 6.3 years for children from slum community $(p<0.01)$. Mean monthly income of slum residents was $\$ 669$, compared to $\$ 1005$ for middle/low-income and $\$ 3500$ for high-income residents $(p<0.01)$. Slum residents were more likely to be geocoded as living in a slum census tract (AGSN) compared to other groups $(p<0.01)$.

Of the 598 children included in this study, 221 (37\%) were colonized with S. aureus, of which 49 (22\%) were colonized with MRSA. All MRSA strains were susceptible to clindamycin, nitrofurantoin, and rifampin. Lower resistance frequencies among MRSA were observed for ciprofloxacin, chloramphenicol (2\% each), gentamicin, trimethoprim-sulfamethoxazole (6.1\% each), and tetracycline $(12.2 \%)$. Non-susceptibility to erythromycin made up 42.9\%, comprising two (4.1\%) intermediate and 19 (38.8\%) resistant isolates. Multidrug resistance was observed in eight (16.3\%) MRSA strains, which presented resistance to 
Table 1 Patient characteristics by socioeconomic status for pediatric patients examined at private and public clinics - Niterói, RJ, Brazil, 2014

\begin{tabular}{|c|c|c|c|c|c|c|c|c|c|}
\hline \multirow[t]{2}{*}{ Demographic characteristic } & \multicolumn{2}{|c|}{$\begin{array}{l}\text { High-income } \\
\text { patient }\end{array}$} & \multicolumn{2}{|c|}{$\begin{array}{l}\text { Middle/low-income } \\
\text { patient }\end{array}$} & \multicolumn{2}{|c|}{$\begin{array}{l}\text { Slum resident } \\
\text { patient }\end{array}$} & \multicolumn{2}{|l|}{ Total } & \multirow[t]{2}{*}{$\begin{array}{l}P \\
\text { value }\end{array}$} \\
\hline & $\mathrm{n}$ & $\%$ & $\mathrm{n}$ & $\%$ & $\mathrm{n}$ & $\%$ & $\mathrm{n}$ & $\%$ & \\
\hline Male & 151 & 52 & 64 & 51 & 90 & 49 & 305 & 51 & 0.83 \\
\hline Mean age in years (SD) & 3.2 & 4 & 5.9 & 5 & 6.3 & 5 & 4.8 & 5 & $<0.01$ \\
\hline Child race or ethnicity & & & & & & & & & $<0.01$ \\
\hline White & 209 & 72 & 52 & 42 & 58 & 32 & 319 & 53 & \\
\hline Mixed (pardo or mestiço) & 63 & 22 & 58 & 46 & 108 & 59 & 229 & 38 & \\
\hline Black & 18 & 6 & 15 & 12 & 17 & 9 & 50 & 8 & \\
\hline Attends childcare center & 53 & 18 & 21 & 17 & 18 & 10 & 92 & 15 & 0.04 \\
\hline Child attends a public childcare center or school (vs private) & 9 & 6 & 55 & 67 & 93 & 79 & 157 & 26 & $<0.01$ \\
\hline Stable income & 270 & 93 & 105 & 85 & 130 & 71 & 505 & 84 & $<0.01$ \\
\hline Mean monthly household income in USD (SD) & 3500 & 2985 & 1005 & 1277 & 669 & 500 & 2141 & 2578 & $<0.01$ \\
\hline Receives government financial assistance (Bolsa Família) & 3 & 1 & 41 & 33 & 76 & 43 & 120 & 20 & $<0.01$ \\
\hline Geocoded distance to slum census tract & & & & & & & & & $<0.01$ \\
\hline Within slum census tract & 1 & 0.4 & 19 & 16 & 30 & 19 & 50 & 8 & \\
\hline Within $50 \mathrm{~m}$ & 6 & 2 & 12 & 10 & 66 & 41 & 84 & 14 & \\
\hline Within $100 \mathrm{~m}$ & 8 & 3 & 18 & 15 & 15 & 9 & 41 & 7 & \\
\hline More than $100 \mathrm{~m}$ & 250 & 94 & 69 & 59 & 49 & 31 & 368 & 62 & \\
\hline Number of persons in household & & & & & & & & & $<0.01$ \\
\hline 2 (Single parent/guardian) & 10 & 4 & 6 & 5 & 11 & 6 & 27 & 5 & \\
\hline 3 or 4 & 225 & 78 & 74 & 59 & 109 & 60 & 408 & 68 & \\
\hline 5 or more & 55 & 19 & 45 & 36 & 63 & 34 & 163 & 27 & \\
\hline Other children 5 years or younger in household & 55 & 19 & 37 & 30 & 55 & 30 & 147 & 25 & 0.01 \\
\hline Residence type & & & & & & & & & $<0.01$ \\
\hline Apartment & 100 & 35 & 2 & 2 & 0 & 0 & 102 & 17 & \\
\hline House & 189 & 65 & 123 & 98 & 183 & 100 & 495 & 83 & \\
\hline Education of guardian & & & & & & & & & $<0.01$ \\
\hline Illiterate or incomplete primary education & 0 & 0 & 34 & 27 & 66 & 36 & 100 & 17 & \\
\hline Complete primary education or incomplete secondary education & 4 & 1 & 35 & 28 & 44 & 24 & 83 & 14 & \\
\hline Complete secondary education or incomplete higher education & 117 & 40 & 41 & 33 & 63 & 35 & 221 & 37 & \\
\hline Complete higher education & 169 & 58 & 14 & 11 & 9 & 5 & 192 & 32 & \\
\hline Employment status of guardian & & & & & & & & & $<0.01$ \\
\hline Employed & 254 & 85 & 75 & 60 & 120 & 66 & 440 & 74 & \\
\hline Unemployed & 8 & 3 & 9 & 7 & 8 & 4 & 25 & 4 & \\
\hline Stay-at-home parent/guardian & 30 & 10 & 30 & 24 & 47 & 26 & 107 & 18 & \\
\hline Other (retired, student etc.) & 7 & 2 & 11 & 9 & 6 & 3 & 24 & 4 & \\
\hline Animals living in the house & 119 & 41 & 70 & 56 & 87 & 48 & 276 & 46 & 0.02 \\
\hline Total & 290 & 49 & 125 & 21 & 183 & 31 & 598 & 100 & \\
\hline
\end{tabular}

SD Standard deviation

beta-lactams and to other two or three classes of antimicrobial agents. BHS colonization was observed in 24 (4\%) of the 598 patients. All BHS isolates were susceptible to all antimicrobial agents tested.
Differences in BHS serogroups and S. aureus SCCmec types

Table 2 shows the difference in colonization with BHS serogroups and MRSA SCCmec type distribution. BHS 
Table 2 Colonization with Staphylococcus aureus and beta-hemolytic streptococci and distribution of MRSA SCCmec types by socioeconomic status for pediatric patients examined at private and public clinics - Niterói, RJ, Brazil, 2014

\begin{tabular}{|c|c|c|c|c|c|c|c|}
\hline \multirow[t]{2}{*}{ Characteristic } & \multicolumn{2}{|c|}{ High-income patient } & \multicolumn{2}{|c|}{ Middle/low-income patient } & \multicolumn{2}{|c|}{ Slum resident patient } & \multirow{2}{*}{$\begin{array}{l}P \\
\text { value }\end{array}$} \\
\hline & $n$ & $\%$ & $\mathrm{~N}$ & $\%$ & $\mathrm{~N}$ & $\%$ & \\
\hline S. aureus colonization & 94 & 32 & 51 & 41 & 76 & 42 & 0.09 \\
\hline MSSA colonization & 77 & 27 & 33 & 26 & 62 & 34 & 0.19 \\
\hline MRSA colonization & 17 & 6 & 18 & 14 & 14 & 8 & 0.01 \\
\hline MRSA SCCmec type & & & & & & & 0.31 \\
\hline Type I & 0 & 0 & 1 & 6 & 0 & 0 & \\
\hline Type II & 0 & 0 & 1 & 6 & 0 & 0 & \\
\hline Type III & 1 & 6 & 1 & 6 & 1 & 7 & \\
\hline Type IV & 13 & 77 & 15 & 83 & 13 & 93 & \\
\hline Type V & 3 & 18 & 0 & 0 & 0 & 0 & \\
\hline Presence of $\mathrm{PVL}$ gene in MRSA isolate & 4 & 19 & 2 & 10 & 4 & 21 & 0.57 \\
\hline Streptococcal colonization & 8 & 3 & 7 & 6 & 9 & 5 & 0.30 \\
\hline Streptococcal Lancefield group & & & & & & & 0.001 \\
\hline Group A & 8 & 100 & 1 & 14 & 6 & 67 & \\
\hline Group B & 0 & 0 & 5 & 71 & 0 & 0 & \\
\hline Group C or G & 0 & 0 & 1 & 14 & 3 & 33 & \\
\hline
\end{tabular}

MSSA methicillin-susceptible Staphylococcus aureus, MRSA methicillin-resistant Staphylococcus aureus, PVL Panton-Valentine leucocidin

colonization did not differ significantly between SES $(p$ $=0.30$ ). However, BHS serogroup differed significantly among the three SES groups $(p<0.01)$. GAS was the most frequent BHS found among the population investigated, comprising 15 (62.5\%) of the 24 isolates.

Colonization with $S$. aureus varied between 32 and $42 \%$ among SES groups, but it was not statistically significant $(p=0.09)$. However, colonization with MRSA was more common among middle/low-SES patients $(p=$ 0.01). MRSA SCCmec type IV was the most frequent type across all three SES and all 10 (20.4\%) isolates that had the PVL genes carried this type. All the SCCmec types found among the isolates, but type III, were associated with multidrug-resistant (MDR) strains. Resistant to gentamicin was only observed among the three MDR strains that carried the PVL genes.

\section{Risk factors for MRSA colonization}

Income $(p=0.03)$, income stability $(p=0.01)$, and number of household $(p=0.03)$ were variables associated with MRSA colonization. Age $(p=0.05)$ and receiving government financial assistance $(p=0.05)$ were also included in the multivariable logistic regression analysis as potential confounding factors. In the bivariate regression analysis for all patients, those attending the public clinic and living in a household with an unstable income had significantly higher odds of MRSA colonization (OR = 1.98 , 95\% CI 1.08-3.65 and OR $=2.45$, 95\% CI $1.26-$ 4.76, respectively) (Table 3 ).
However, in the multivariate regression model, neither of these factors remained significant after adjusting for income. Only children from households with a monthly income \$971-\$1938 had a significantly higher adjusted odds of MRSA colonization in comparison to children from households with a monthly income of $\$ 0-\$ 970$ $(\mathrm{AOR}=3.40,95 \% \mathrm{CI} 1.45-7.98)$. In the stratified logistic regression analysis by clinic, no risk factor for MRSA colonization was significant among patients examined at the private clinic (data not shown). For patients examined at the public clinic, living in a household with a monthly income of $\$ 971-\$ 1938$ continued to be a significant risk factor for MRSA colonization in the adjusted model $(\mathrm{AOR}=4.84,95 \%$ CI 1.90-12.31). Slum residence was found to be a protective factor among children who visited the public clinic $(\mathrm{AOR}=0.40,95 \%$ CI 0.17-0.97).

\section{Risk factors for BHS colonization}

Among all patients, BHS colonization by any serogroup was associated with age $\geq 5$ years and school attendance $(p<0.05)$. Among clinical characteristics for all patients, attending the clinic due to symptoms/illness $(p=0.01)$, having an earache $(p=0.03)$, sore throat $(p<0.01)$, upper respiratory tract infection $(p=0.04)$ or rhinitis $(p=0.01)$ were associated with the presence of BHS (data not shown). Being 5 years of age or older and attending school were found to be significant risk factors for BHS colonization in the multivariate regression analysis 
Table 3 Risk factors for MRSA colonization for all pediatric patients and only for pediatric patients examined at the public clinic

\begin{tabular}{|c|c|c|c|c|c|c|c|c|}
\hline \multirow[t]{2}{*}{ Risk factor for MRSA colonization } & \multicolumn{4}{|l|}{ All patients } & \multicolumn{4}{|l|}{ Public clinic only } \\
\hline & Unadjusted OR & $95 \% \mathrm{Cl}$ & Adjusted OR & $95 \% \mathrm{Cl}$ & Unadjusted OR & $95 \% \mathrm{Cl}$ & Adjusted OR & $95 \% \mathrm{Cl}$ \\
\hline Attends public clinic & 1.98 & $1.08-3.65$ & 2.23 & $0.94-5.30$ & NA & NA & NA & NA \\
\hline Does not have stable income & 2.45 & $1.26-4.76$ & 2.05 & $0.93-4.55$ & 2.20 & $1.02-4.77$ & 2.62 & $0.99-6.98$ \\
\hline \multicolumn{9}{|l|}{ Monthly household income (\$USD) } \\
\hline$\$ 0-\$ 970$ & 1.00 & - & 1.00 & - & 1.00 & - & 1.00 & - \\
\hline$\$ 971-\$ 1938$ & 1.97 & $0.96-4.07$ & 3.40 & $1.45-7.98$ & 4.44 & $1.84-10.71$ & 4.84 & $1.90-12.31$ \\
\hline$\$ 1939$ or more & 0.61 & $0.27-1.40$ & 1.36 & $0.46-4.04$ & NA & NA & NA & NA \\
\hline Self-reported slum residence & 0.90 & $0.47-1.72$ & - & - & 0.52 & $0.25-1.09$ & 0.40 & $0.17-0.97$ \\
\hline Five years of age or older & 1.74 & $0.97-3.13$ & - & - & 1.85 & $0.86-3.99$ & - & - \\
\hline Receives government financial assistance & 1.89 & $0.99-3.61$ & - & - & 1.51 & $0.72-3.19$ & - & - \\
\hline Five or more household members & 1.79 & $0.98-3.27$ & - & - & 1.25 & $0.59-2.63$ & - & - \\
\hline
\end{tabular}

OR Odds ratio, $\mathrm{Cl}$ Confidence interval. Hosmer and Lemeshow Goodness-of-Fit Test $p$-value for all patients model $=0.693$, for public clinic only $=0.911$. Dash (-) indicates not included in the analysis or not applicable. NA refers to categories for which there were no subjects, and therefore, odd ratios could not to be calculated

$(\mathrm{AOR}=16.36,95 \% \mathrm{CI} 3.77-70.98$ and $\mathrm{AOR}=6.46,2.52-$ 16.54, respectively) (Table 4).

\section{Discussion}

We observed differences in $S$. aureus and BHS colonization among pediatric patients from different SES communities living in the same city in Brazil. Middle/ low SES patients were found to be more frequently colonized with these bacteria than high-income and slum resident patients. Bacterial isolates from middle/low-income children had the highest diversity in both MRSA genetic characteristics and BHS serogroups, covering four of the five SCCmec types and all BHS serogroups. In Brazil, middle/low SES neighborhoods tend to be on the border of slums, sometimes referred to as the "periphery", between industrial or commercial zones and high SES neighborhoods. Despite the relation of slum areas with low sanitation resources [14], slum residence was not a risk factor for MRSA colonization among children attended in the public clinic.

Differences in $S$. aureus, MRSA, and S. pyogenes colonization prevalence between SES communities in Niterói mirror differences in the prevalence of these pathogens between high-income and low- and middle-income countries (LMIC). Here, S. aureus colonization prevalence was $32 \%$ among high-income SES children. This frequency is similar to that found in healthy or outpatient children in high-income countries, such as USA (35-37\%) [24, 25], Canada (24\%) [26], Taiwan (29\%) [27], China (28\%) [28], as well as in some LMIC, such as India (35\%) [29], Botswana (52\%) [30], Iran (28\%) [31], Gambia (25\%) [32] and Angola (44\%)

Table 4 Characteristics associated with the presence of beta-hemolytic streptococcal among pediatric patients examined at private and public clinics - Niterói, RJ, Brazil, 2014

\begin{tabular}{|c|c|c|c|c|}
\hline Characteristic & Unadjusted OR & $95 \% \mathrm{Cl}$ & Adjusted OR & $95 \% \mathrm{Cl}$ \\
\hline Attends public clinic & 1.70 & $0.73-3.94$ & - & - \\
\hline 5 years of age or older & 19.30 & 4.49-82.91 & 16.36 & $3.77-70.98$ \\
\hline Attends school & 14.61 & $3.40-62.71$ & 6.46 & $2.52-16.54$ \\
\hline \multicolumn{5}{|l|}{ Employment status } \\
\hline Employed & 1.00 & - & - & - \\
\hline Stay-at-home & 0.48 & $0.11-2.09$ & - & - \\
\hline Other & 2.83 & $1.00-8.05$ & - & - \\
\hline Attending the clinic due to symptoms/illness (vs. routine) & 3.10 & $1.36-7.10$ & - & - \\
\hline Earache & 5.33 & $1.43-19.84$ & - & - \\
\hline Sore throat & 8.97 & $3.67-21.89$ & - & - \\
\hline Upper respiratory tract infection & 2.33 & $1.00-5.40$ & - & - \\
\hline Rhinitis & 2.86 & $1.26-6.52$ & - & - \\
\hline
\end{tabular}

Dash (-) indicates not included in the analysis or not applicable $O R$ Odds ratio. Hosmer and Lemeshow Goodness-of-Fit Test $p$-value $=0.414$ Cl Confidence interval 
[33]. However, the colonization frequency (40\%) found among middle/low-income SES group and slum residents was higher than found in most of these countries, but similar to those found among public childcare centers in Brazil (47-48\%) [22, 34]. A study in Iran also found lower income to be independently associated with S. aureus colonization frequency [31].

MRSA colonization among all SES groups (8.1\%) in Niterói was higher than frequencies observed in high-income populations ( $\leq 1 \%$ ), such as in USA, Canada, northern Europe, and Hong Kong [28]. However, the difference in colonization prevalence between high and low SES groups observed in the present study (6\% vs. $14 \%)$ reflects differences in prevalence among children from these high-income populations compared with $6-29 \%$ in populations from LMICs, such as Iran, Botswana, Angola, India [29-31, 33, 35], and public childcare centers in Brazil [22, 34].

In general, MRSA strains had low frequency of resistance to other antimicrobial agents, except to erythromycin. SCCmec types IV and V are frequently found in CA-MRSA [34] and, in the present study, type IV was found in the majority $(84 \%)$ of the MRSA strains. The prevalence of PVL-positive strains is usually high among CA-MRSA involved in severe diseases, and may reach as much as $90 \%$ [10]. In this study, we detected the PVL genes among $20 \%$ of the MRSA strains. Since we focused on colonization isolates, the genotypes responsible for colonization may differ from those associated with invasive/severe diseases.

BHS colonization frequency was low (4\%), similar to another study conducted in southern Brazil (5.6\%) [35]. However, the small sample size limited our ability to investigate differences in colonization and risk factors by SES. None of the isolates was resistant to any antimicrobial agent tested. Of note, none of the children colonized with GAS had a household history of rheumatic fever, a disease commonly associated with GAS in developing countries [1]. Interestingly, groups B, C and G streptococci, which also colonize cattle, dogs, and other mammals [2], were only found among middle/low SES children and slum residents. Most participants' legal guardians did not report having animals in the house, but the presence of these bacteria could represent exposure to non-domesticated animals or animal products through poor living conditions or contaminated food.

A major limitation of this study is that some children with symptoms may have the disease caused by the bacteria investigated, especially BHS and sore throat. However, colonization is usually the first step of the infectious process and viruses cause most of the upper respiratory tract diseases. If we excluded symptomatic children from the analysis, we would exclude patients with viral infections. Also, the prevalence of children with symptoms did not differ between subpopulations and, therefore, does not affect the main conclusions of this report. In addition, parents may be more likely to take their children in for routine care when the child has an acute illness, resulting in a higher likelihood of bacterial colonization among our study population. However, these factors are likely to occur in both private and public pediatric populations and we would not expect them to decrease the association with SES found in the present study. Another important limitation was the difference in age between the private and public clinics, given older children are more likely to be colonized with BHS [11]. This was further demonstrated in the present study by age $>5$ years and attending school being risk factors for BHS colonization. Finally, the classification of pediatric patients into three SES groups may be a possible limitation, since self-reported residence location and type of clinic attended do not assure the socioeconomic status of the patients; however, the criteria we used to divide the patients into three subpopulations are very well described and support our analyses.

\section{Conclusions}

Our study demonstrates that subpopulations from different SES strata within the same city may have different exposures or risk factors for bacterial transmission and drug resistance. Children living in middle/low SES communities were more likely to be colonized with $S$. aureus, MRSA, and BHS. We also observed variation among BHS serogroups and MRSA SCCmec types. While living conditions in slum communities would suggest they are at higher risk, residents who live on the periphery of slums or living at the intersection of extreme poverty and high income were shown to be at higher risk for both bacterial colonization and drug resistance. This study also supports the importance of including a representative sample of different SES subpopulations for research on disease transmission or prevalence studies in cities with high income inequality. Public health officials also should consider differences in transmission across SES subpopulations when developing public health interventions and conducting outbreak investigations for bacterial infections.

\section{Abbreviations \\ AGSN: Aglomerados subnormais; AOR: Adjusted odds ratio; BHS: Beta- hemolytic streptococci; BRL: Brazilian Real; GAS: Group A streptococci; GBS: Group B streptococci; GDP: Gross domestic product; LMIC: Low- and middle-income countries; MRSA: Methicillin-resistant Staphylococcus aureus; OR: Odds ratio; SCCmec: Staphylococcal chromosome cassette mec; SES: Socioeconomic status; USD: US Dollar}

\section{Acknowledgements}

The authors would like to thank Dr. Carlos A. Campbell and Dr. Paulo José Tardin Monnerat for their gracious invitation to conduct this study in their clinics and their continued support of our projects. We would also like to acknowledge 
lasmim Almeida and Thamiris Santana of the Universidade Federal Fluminense for their much appreciated participation in data collection.

\section{Funding}

This project was supported by NIH Research Training Grant \# R25 TW009338 (Global Health Equity Scholars Program) funded by the Fogarty International Center and the Office of AIDS Research at the National Institutes of Health. Funders have not contributed to the design of the study and collection, analysis, and interpretation of data and in writing the manuscript.

\section{Availability of data and materials}

The datasets used and/or analyzed during the current study available from the corresponding author on reasonable request.

\section{Authors' contributions}

FPGN, MAM, RRB, FAA, CAAC and LWR contributed to the overall design of the study. FPGN, MAM, GRP, AFMS, MGP, CAAC, and FAA participated in field and clinical aspects of the study. FPGN, GRP, MGP, AFMS, MFNF and RRB performed experimental analyses. MAM performed statistical analyses. FPGN and MAM drafted the manuscript. GRP, CAAC and LWR helped draft the manuscript. All authors read and approved the final manuscript.

\section{Ethics approval and consent to participate}

The Ethics Committees of the University of California, Berkeley and Universidade Federal Fluminense (CAAE: 26823614.2.0000.5243) approved this study. Legal guardians of all participants provided written consent.

\section{Consent for publication}

Not applicable.

\section{Competing interests}

The authors declare that they have no competing interests.

\section{Publisher's Note}

Springer Nature remains neutral with regard to jurisdictional claims in published maps and institutional affiliations.

\section{Author details}

${ }^{1}$ Instituto Biomédico, Universidade Federal Fluminense, Niterói, RJ, Brazil. ${ }^{2}$ School of Public Health, University of California, Berkeley, CA, USA.

${ }^{3}$ Laboratório Universitário Rodolpho Albino, Universidade Federal Fluminense, Niterói, RJ, Brazil. ${ }^{4}$ Faculdade de Medicina, Universidade Federal Fluminense, Niterói, RJ, Brazil.

\section{Received: 5 February 2019 Accepted: 16 May 2019}

Published online: 29 May 2019

\section{References}

1. Carapetis JR, Steer AC, Mulholland EK, Weber M. The global burden of group a streptococcal diseases. Lancet Infect Dis. 2005;5:685-94.

2. Cimolai N, MacCulloch L, Damm S. The epidemiology of beta-haemolytic non-group a streptococci isolated from the throats of children over a oneyear period. Epidemiol Infect. 1990;104:119-26.

3. Tong SY, Davis JS, Eichenberger E, Holland TL, Fowler VG Jr. Staphylococcus aureus infections: epidemiology, pathophysiology, clinical manifestations, and management. Clin Microbiol Rev. 2015;28:603-61.

4. Davis MF, Iverson SA, Baron P, et al. Household transmission of meticillinresistant Staphylococcus aureus and other staphylococci. Lancet Infect Dis. 2012;12:703-16.

5. Kao K-C, Chen C-B, Hu H-C, Chang H-C, Huang C-C, Huang Y-C. Risk factors of methicillin-resistant Staphylococcus aureus infection and correlation with nasal colonization based on molecular genotyping in medical intensive care units: a prospective observational study. Medicine (Baltimore). 2015;94: e1100.

6. Kaplan SL. Staphylococcus aureus infections in children: the implications of changing trends. Pediatrics. 2016;137(4):e20160101.

7. Gerber JS, Coffin SE, Smathers SA, et al. Trends in the incidence of methicillin-resistant Staphylococcus aureus infection in Children's hospitals in the United States. Clin Infect Dis. 2009;49:65-71.
8. Hamdy RF, Hsu AJ, Stockmann C, et al. Epidemiology of methicillin-resistant Staphylococcus aureus bacteremia in children. Pediatrics. 2017;139(6): e20170183.

9. Baig S, Johannesen TB, Overballe-Petersen S, Larsen J, Larsen AR, Stegger M. Novel SCCmec type XIII (9A) identified in an ST152 methicillin-resistant Staphylococcus aureus. Infect Genet Evol. 2018;61:74-6.

10. Bhatta DR, Cavaco LM, Nath G, Kumar K, Gaur A, Gokhale S, Bhatta DR. Association of Panton valentine Leukocidin (PVL) genes with methicillin resistant Staphylococcus aureus (MRSA) in Western Nepal: a matter of concern for community infections (a hospital based prospective study). BMC Infect Dis. 2016;16:199.

11. Efstratiou ALT. Epidemiology of Streptococcus pyogenes. In: SD FJJ, Fischetti VA, editors. Streptococcus pyogenes: Basic Biology to Clinical Manifestations. Oklahoma City: University of Oklahoma Health Sciences Center; 2016.

12. Seale AC, Bianchi-Jassir F, Russell NJ, et al. Estimates of the burden of group B streptococcal disease worldwide for pregnant women, stillbirths, and children. Clin Infect Dis. 2017;65:S200-19.

13. Bowen AC, Mahé A, Hay RJ, et al. The global epidemiology of impetigo: a systematic review of the population prevalence of impetigo and pyoderma. PLoS One. 2015;10:e0136789.

14. Unger A, Riley LW. Slum health: from understanding to action. PLoS Med. 2007;4:e295.

15. Brazilian Institute of Geography and Statistics. 2010 Demographic census_subnormal settlements territorial information. p. 2011. https:// censo2010.ibge.gov.br/apps/agsn2/. Accessed 15 Mar 2014

16. Brazilian Institute of Geography and Statistics. Niterói - Infographics: General data of the municipality. 2010. https://cidades.ibge.gov.br/brasil/rj/niteroi/ panorama. Accessed 15 Mar 2014.

17. Brazilian Ministry of Health. DATASUS - Gini index of household income per capita - Rio De Janeiro. 2010. http://tabnet.datasus.gov.br/cgi/ibge/censo/ cnv/ginirj.def. Accessed 15 Mar 2014.

18. Clinical and Laboratory Standards Institute. Perfomance standards for antimicrobial susceptibility testing. 28th ed. Wayne: Clinical and Laboratory Standards Institute; 2018

19. Oliveira DC, De Lencastre H. Multiplex PCR strategy for rapid identification of structural types and variants of the mec element in methicillin-resistant Staphylococcus aureus. Antimicrob Agents Chemother. 2002;46:2155-61.

20. Lina G, Piémont Y, Godail-Gamot F, et al. Involvement of Panton-valentine leukocidin-producing Staphylococcus aureus in primary skin infections and pneumonia. Clin Infect Dis. 1999;29:1128-32.

21. Facklam R. What happened to the streptococci: overview of taxonomic and nomenclature changes. Clin Microbiol Rev. 2002;15:613-30.

22. Braga ED, Aguiar-Alves F, de Freitas Mde F, et al. High prevalence of Staphylococcus aureus and methicillin-resistant S. aureus colonization among healthy children attending public daycare centers in informal settlements in a large urban center in Brazil. BMC Infect Dis. 2014;14:538.

23. Tartof SY, Reis JN, Andrade AN, Ramos RT, Reis MG, Riley LW. Factors associated with group a Streptococcus emm type diversification in a large urban setting in Brazil: a cross-sectional study. BMC Infect Dis. 2010;10:327.

24. Gorwitz RJ, Kruszon-Moran D, McAllister SK, et al. Changes in the prevalence of nasal colonization with Staphylococcus aureus in the United States, 20012004. J Infect Dis. 2008;197:1226-34.

25. Kuehnert MJ, Kruszon-Moran D, Hill HA, et al. Prevalence of Staphylococcus aureus nasal colonization in the United States, 2001-2002. J Infect Dis. 2006; 193:172-9.

26. Shahin R, Johnson IL, Jamieson F, McGeer A, Tolkin J, Ford-Jones EL. Methicillinresistant Staphylococcus aureus carriage in a child care center following a case of disease. Toronto child care center study group. Arch Pediatr Adolesc Med. 1999; 153:864-8.

27. Tsai MS, Chen CJ, Lin TY, Huang YC. Nasal methicillin-resistant Staphylococcus aureus colonization among otherwise healthy children aged between 2 months and 5 years in northern Taiwan, 2005-2010. J Microbiol Immunol Infect. 2018;51:756-62.

28. Ho PL, Chiu SS, Chan MY, et al. Molecular epidemiology and nasal carriage of Staphylococcus aureus and methicillin-resistant S. aureus among young children attending day care centers and kindergartens in Hong Kong. J Inf Secur. 2012;64:500-6.

29. Dey S, Rosales-Klintz S, Shouche S, Pathak JP, Pathak A. Prevalence and risk factors for nasal carriage of Staphylococcus aureus in children attending anganwaries (preschools) in Ujjain, India. BMC Res Notes. 2013;6:265.

30. Reid MJA, Fischer RSB, Mannathoko N, et al. Prevalence of Staphylococcus aureus nasal carriage in human immunodeficiency virus-infected and 
uninfected children in Botswana: prevalence and risk factors. Am J Trop Med Hyg. 2017;96:795-801.

31. Mobasherizadeh S, Shojaei $H$, Havaei SA, et al. Nasal carriage screening of community-associated methicillin resistant Staphylococcus aureus in healthy children of a developing country. Adv Biomed Res. 2016;5:144.

32. Ebruke C, Dione MM, Walter B, et al. High genetic diversity of Staphylococcus aureus strains colonising the nasopharynx of Gambian villagers before widespread use of pneumococcal conjugate vaccines. BMC Microbiol. 2016;16:38.

33. Conceicao T, Coelho C, Santos Silva I, de Lencastre H, Aires-de-Sousa M. Methicillin-resistant Staphylococcus aureus in the Community in Luanda, Angola: blurred boundaries with the hospital setting. Microb Drug Resist. 2016;22:22-7.

34. Carvalho SP, Almeida JB, Andrade Y, et al. Community-acquired methicillinresistant Staphylococcus aureus carrying SCCmec type IV and V isolated from healthy children attending public daycares in northeastern Brazil. Braz J Infect Dis. 2017:21:464-7.

35. Merlini AB, Stocco CS, Schafranski MD, et al. Prevalence of group a Betahemolytic Streptococcus oropharyngeal colonization in children and therapeutic regimen based on Antistreptolysin levels: data from a City from southern Brazil. Open Rheumatol J. 2014;8:13-7.

Ready to submit your research? Choose BMC and benefit from:

- fast, convenient online submission

- thorough peer review by experienced researchers in your field

- rapid publication on acceptance

- support for research data, including large and complex data types

- gold Open Access which fosters wider collaboration and increased citations

- maximum visibility for your research: over $100 \mathrm{M}$ website views per year

At BMC, research is always in progress.

Learn more biomedcentral.com/submissions 